\title{
P02.167. Long term evaluation of homeopathy on post treatment impairment of pulmonary tuberculosis
}

\author{
S Sharma ${ }^{1 *}$, N Sharma $^{2}$ \\ From International Research Congress on Integrative Medicine and Health 2012 \\ Portland, Oregon, USA. 15-18 May 2012
}

\section{Purpose}

Previous studies show that treated and cured pulmonary tuberculosis patients do suffer from pulmonary impairment, lower health related quality of life, disability and long term morbidity, thus responsible for a majority of the disease burden. Despite this, no effective management is available for most of the patients. Therefore, the present study was undertaken to evaluate the impact of homeopathy on pulmonary, functional and quality of life status of patients with pulmonary tuberculosis who have completed treatment.

\section{Methods}

Patients who were cured and had completed anti-tuberculosis treatment within a period of 5 years were enrolled in a randomized double-blind placebo-controlled trial. Individualised homeopathy treatment was given to 61 patients and identical placebo to 57 patients. Symptomatic changes, pulmonary function tests, and health related quality of life were assessed prior to treatment, after 6 months of intervention, and followed up for a year after completing the intervention.

\section{Results}

Significant improvement was observed with the homeopathy treatment in FEV1 $(\mathrm{p}<0.001)$, forced vital capacity $(\mathrm{p}<0.001)$, and FEV1/FVC ratio $(\mathrm{p}=0.002)$. Symptom scores for cough and breathlessness were significantly lower with homeopathy than with placebo $(\mathrm{p}<0.001)$. At the end of treatment, patients on homeopathy had increased body weight $(\mathrm{p}<0.0001)$, and better quality of life $(\mathrm{p}<0.05)$ compared with placebo $(\mathrm{p}=0.003)$. Benefits were maintained in the homeopathy group after a year whereas symptoms $(\mathrm{p}<0.01)$ and impact score $(\mathrm{p}<0.001)$ deteriorated in placebo. Physicians visits were reduced in the homeopathy group by $58.0 \%(\mathrm{p}=0.002)$ compared to placebo $(\mathrm{p}<0.0001)$.

\section{Conclusion}

Homeopathy is effective in improving lung capacity and health status. Benefits remain evident after a year. This suggests that homeopathy could make an important contribution to post treatment tuberculosis pulmonary impairment.

\section{Author details}

${ }^{1}$ NMP Medical Research Institute, Jaipur, India. ${ }^{2}$ Brett Research (UK), London, United Kingdom.

Published: 12 June 2012

\section{doi:10.1186/1472-6882-12-S1-P223}

Cite this article as: Sharma and Sharma: P02.167. Long term evaluation of homeopathy on post treatment impairment of pulmonary tuberculosis. BMC Complementary and Alternative Medicine 2012 12(Suppl 1):P223.

${ }^{1}$ NMP Medical Research Institute, Jaipur, India

Full list of author information is available at the end of the article

(c) 2012 Sharma and Sharma; licensee BioMed Central Ltd. This is an Open Access article distributed under the terms of the Creative 